\title{
Spray forming: Science and technology
}

\begin{abstract}
S N OJHA
Department of Metallurgical Engineering, Banaras Hindu University, Varanasi 221005 , India

Abstract. Spray forming involves sequential gas atomization of a melt into a spray of fine droplets and their deposition on a substrate to build up a high-density preform. The rapid solidification inherent in spray deposition generates refined, equiaxed and low segregation microstructures. A number of promising features of this near-net shape manufacturing process are highlighted and compared, wherever possible, with the conventional casting and PM techniques. Some commercial nozzles used to create spray and mechanisms associated with spray generation are described. The consolidation of the droplets and the development of the microstructure in the deposit are primarily governed by the nature of the spray and the thermal state of droplets on the deposition surface. Several microstructural characteristics of the deposit are presented and their origin in spray deposition is discussed.
\end{abstract}

Keywords. Spray forming; near-net shape; atomization; droplets; deposition; nozzles; heat flow; microstructures.

\section{Introduction}

In recent years, the global energy crisis and a rapid change in high-tech industries are giving way to new energy efficient manufacturing processes. The primary requirement of any such process necessitates production of near-net shape preform in less number of steps. Although, the generic metal casting processes fulfil this criteria, a large segregate spacing and a coarse grain structure severely limit the direct application of a cast product in critical service conditions. Consequent microstructural refinement is then achieved by a number of secondary processing operations. Besides considerable energy consumption and a low yield of finished products, each operation requires careful process control.

Alternatively, rapid solidification (RS) processing of melt provides considerable microstructural homogeneity and refinement in grain size in a large number of alloys (Anantharaman and Suryanarayana 1971; Jones 1973, 1986). Amongst several RS processes developed in the past, the potential of melt spinning (Chen and Miller 1970) and inert gas atomization (Savage and Froes 1984; Lawley 1986) is emphasized to produce RS alloys on a commercial scale. In melt spinning a stable jet of liquid metal is brought into contact with the surface of a fast rotating disc where the melt spreads into thin film and subsequent to solidification gets released. Rapid cooling of the melt in this process occurs by conductive heat transfer through the disc material. The cooling rate of the melt often exceeds $10^{5} \mathrm{Ks}^{-1}$. The resultant product is either in the form of particulates or continuous ribbon.

In melt atomization process generally a stream of liquid metal is disrupted by high-energy gas jets into fine droplets. These are cooled by gas stream during free flight to generate spherical powders. RS effects are naturally produced in small size powders due to their increased surface-to-volume ratio and high heat exchange rate at the droplet-gas interface (Clyne et al 1984; Ricks et al 1986). In addition, large undercooling induced in droplets also aids in the development of RS microstructures 

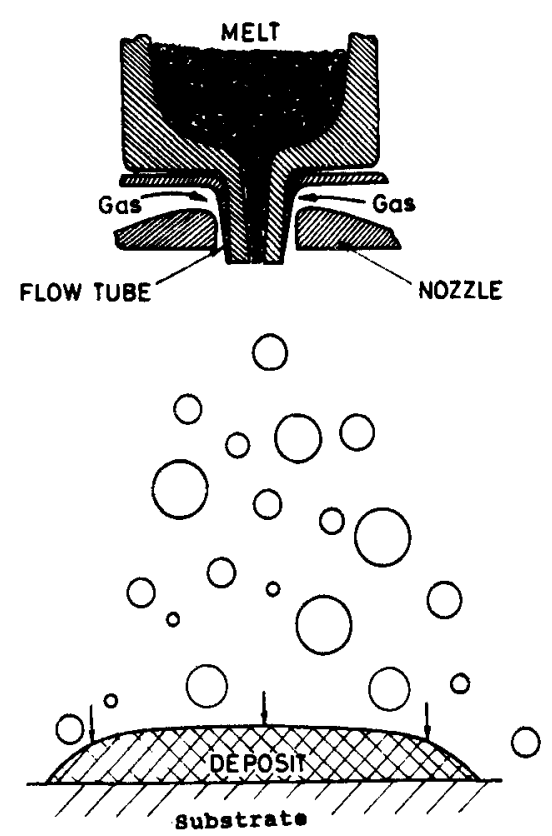

Figure 1. Schematic diagram of the spray forming process.

(Pandey and Ojha 1991). The RS powders or particulates produced by these processes require their consolidation into a near-net shape preform employing powder metallurgy (PM) methods. This involves many intermediate steps e.g. sieving, canning and degassing of powders prior to hot extrusion or hot isostatic pressing. At the same time highly specialized and expensive equipments required in the consolidation of RS powders/particulates limit their easy acceptability by industries.

A novel RS process which overcomes these problems to a great extent is the spray forming which is now emerging as a viable alternative to several RS/PM methods. In this process, the melt, in the form of a spray of fine droplets, is accelerated towards a solid substrate to impinge and consolidate into a thick high density preform (Singer 1972). The atomization and droplet consolidation in this way takes place sequentially in a single operation (figure 1). The RS effects inherent in atomization and droplets deposition generate a relatively more homogeneous microstructures characterized by a fine grain size with evenly distributed second phase precipitates. This aspect is considered beneficial to improve the workability of the preform. Several promising features of the spray forming process have stimulated considerable interest to exploit its potential in the development of strategic materials (Leatham et al 1991). The purpose of this paper is to present an overview of spray forming process in relation to the work being carried out at the Banaras Hindu University, Varanasi.

\section{Historical development and current status}

The principle of spray forming was pioneered by Singer (1970) and his co-workers (Brooks et al 1977a, b; Singer and Evans 1983) at the University College of Swansea in the early 1970's. These investigators established the feasibility of the production of 
strips directly from the molten metal. The Al-melt was atomized by nitrogen gas in the pressure range 0.6 to $1.0 \mathrm{MPa}$. The spray of droplets, usually 100 to $150 \mu \mathrm{m}$ size, was collected over a stationary substrate placed at $0.40 \mathrm{~m}$ from the atomization zone. Williams (1980) observed considerable porosity and variation in thickness across the width of the as-deposited strips. The strip was subsequently fed to a roll gap for further reduction in thickness and to minimize the porosity.

Several years later, Osprey Metals Work was set-up as a commercial enterprise in UK. The plant employed the early idea of Singer for the production of forging preforms. However, in the early stage of development, this process was directed only to the production of preform without recognition of its intrinsic component of rapid solidification. It was only in the 1980's, the spray atomization and deposition was considered as a bonafide $\mathrm{RS}$ process. The convective cooling was primarily responsible for high cooling rate in atomized droplets. This understanding generated considerable momentum in rapid development of spray forming process.

Subsequent researches based on the early spray forming process resulted in development of the liquid dynamic compaction (LDC) process by Lavernia and Grant $(1986,1988)$. It is worthwhile to point out here that LDC, Osprey and spray deposition are the generic names of similar or related processes. The melt in LDC was atomized at high gas pressure to generate the maximum yield of small size droplets in the spray. The cooling rate of a large fraction of droplets reached well within RS regime. Soon after, many investigations proved the potential of spray forming process to achieve superior microstructures and mechanical properties in a variety of special steels (Rickinson et al 1981; Magusar et al 1984), Al-alloys (Ando et al 1986) as well as superalloys (Bricknell 1986). These materials also showed better response to heat treatment.

Today, the spray forming process is being evaluated for commercial production of disc, billet, strip and tube shape preform of a variety of materials (Lawley et al 1990). Controlled manoeuvring of the deposition substrate and optimization of the process variables have provided the capability of this process in direct production of such near-net shape components in a single operation (figure 2). The commercialization of the process is already underway for rolls of high-carbon alloy steels (Ikawa 1990), tubes of stainless steels and superalloys and large size extrusion billets of aluminium alloys (Leatham et al 1991). The process is mainly applied to those alloys which are either difficult to produce by ingot metallurgy, or expensive to produce by PM route. However, the commercial production further necessitates close tolerance in shape and dimension of a component with consistency in the product quality. The future development obviously points in this direction.

\section{Fundamentals of spray forming}

The shape and microstructural features of the preform are largely influenced by the characteristics of the spray. Other than the process variables employed to atomize the melt, the design of atomization nozzle is critical to control the size and size distribution of droplets. Surprisingly, this aspect has not been paid much attention as the design data of the spray nozzle often originate from patent literature (Beddow 1978). Some of the typical gas-metal configurations used in spray forming, characteristics of spray and consolidation of droplets are discussed in the subsequent sections. 

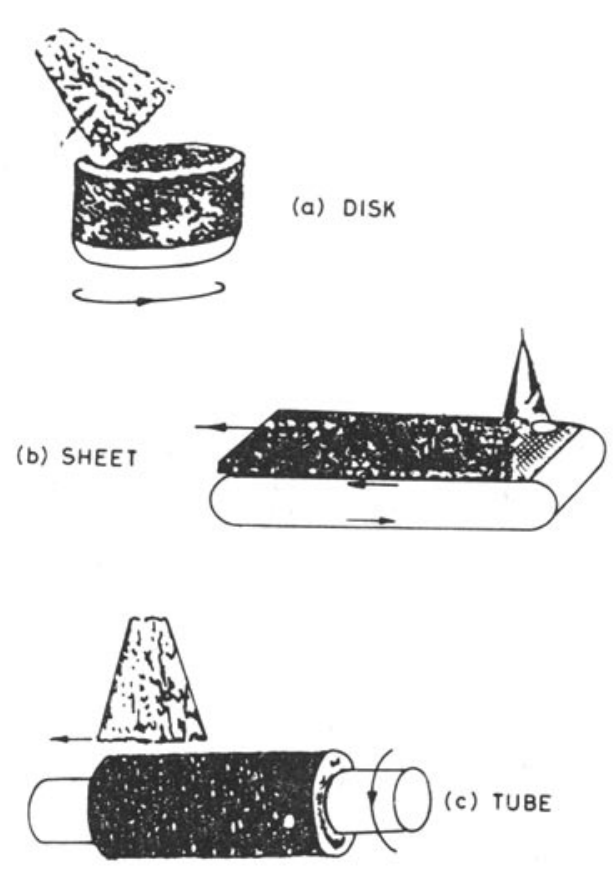

Figure 2. Illustration of the near-net shape production by spray forming.

\subsection{Gas-metal configuration}

The basic objective of a nozzle is to convert the potential energy of the gas into its kinetic energy as efficiently as possible. A large number of nozzle designs are currently available which provide different configurations of gas-metal stream. The gas may take the form of either an annulus which is concentric around the metal stream or form discrete jets. As a result, the commonly used nozzles in spray forming can be broadly classified as 'free fall' and 'confined' types as shown in figure 3.

In free fall design, the melt stream issues from the crucible, falls by gravity about 5 to $30 \mathrm{~cm}$ before it interacts with the gas jets to promote atomization (Klar and Fesko 1984). Since the gas jets strike the stream after travelling a relatively large distance, the gas velocity rapidly decays between the nozzle exit and the point of impact. This promotes inefficient atomization and leads to large size of droplets in the spray. Both annular and discrete jets configurations are common in this design. Although the atomization efficiency is poor in this process, the problem of choking of nozzle is less commonly encountered.

In the confined design of gas-metal configuration, atomization occurs at the orifice of the melt delivery tube which is also known as flow tube. The melt flow is influenced by the gas flow through the nozzle. In this configuration the energy transfer from the gas to metal is highly efficient and more uniform. This arises due to prefilming of the molten metal over the end of the flow tube as well as shorter distance between the gas and metal stream before they interact (figure $3 \mathrm{~b}$ ). In this configuration of gas-metal stream, both the annular and discrete jets can be employed. However, due to rapid attenuation of energy with increasing distance of high-velocity gas jets, confined gas annular designs are frequently used (Unal 1987). The high rate of energy 


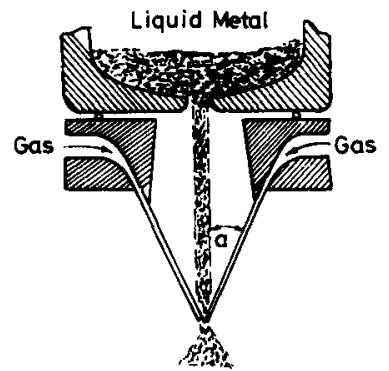

(a) Free falling melt stream

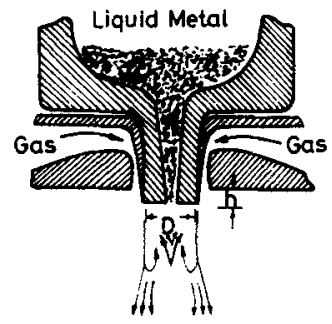

(b) Confined gas melt configuration

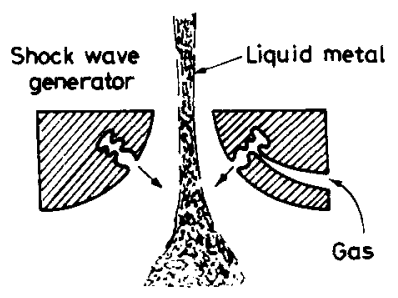

(c) Ultrasonically superimposed gas jets

Figure 3. Diagram showing typical nozzle designs used in spray generation. (a) free-fall, (b) confined and (c) ultrasonic.

transfer from the gas to metal stream results in an increased yield of fine droplets in the spray. However, some demerits of this process include development of back pressure on liquid metal and frequent freezing and erosion of the melt delivery tube. This necessitates careful positioning of the flow tube, its preheating and high superheat of the melt for smooth operation of the process. The effect of several gas-metal configurations on the characteristics of spray-deposit is being evaluated now.

One of the variant of this process utilized ultrasonic pulses in high-velocity gas jets (Grant 1978). Currently this design appears attractive for both production of rapidly solidified powders and spray forming. The high velocity gas pulses are generated on the principle of Hertman shock wave tubes concentrically arranged and focussed on the meit stream (figure 3c). The gas is accelerated to supersonic velocity at pulse frequencies ranging from 60 to $120 \mathrm{kHz}$ prior to impact on the metal stream. As high as 80 to $90 \%$ yield of $<30 \mu \mathrm{m}$ size droplets in the spray has been claimed in the atomization of stainless steels (Grant 1978).

\subsection{Generation of spray of droplets}

A knowledge of the size and size distribution of droplets in the spray is essential to understand the complex heat transfer phenomenon in spray forming. Generally these are controlled by the mechanisms involved in the break-up of the melt in different configurations of the gas-metal stream. See and Johnston (1978) suggested that the liquid break-up in free fall atomization occurs in two distinct stages. The vacuum created above the point of impingement of the gas and stream creates a series of concentric hollow cones. Subsequently dynamic instability of the surface disturbances, 
caused by the turbulence in the gas field, results in the detachment of sheets or ligaments. The ligaments again undergo similar surface instability and break into droplets. These two stages of liquid break-up were described as primary and secondary atomization.

The primary break-up of liquid metal in confined gas-metal configuration occurs by prefilming mechanism. It has been shown by Unal (1989) that the liquid metal runs at the tip of the flow tube in the form of a thin film. The thickness of the film depends on the melt flow rate and physical properties of the liquid. The liquid film subsequently meets the high-velocity gas jets to promote atomization of the melt into coarse droplets. The secondary disintegration of droplets then takes place in high velocity gas field. The exact nature of secondary break-up in atomization is not yet fully understood. Moreover a large amount of experimental data exists (Lane 1951; Gordon 1959) regarding the break-up of non-metallic fluids in allied areas, which can provide valuable insight into metal atomization.

The mode by which secondary break-up occurs depends on the initial droplet size and gas flow condition. For example, a large free falling drop initially becomes unstable due to Taylor instability and disintegrates into fine droplets (Taylor 1950). However, this situation is never encountered in atomization where droplets travel with relatively large velocities. Consequently, the interaction of droplets with high-velocity gas may result in the stripping off the droplet into thin films which further break up from the edges. The stripping action may continue till the droplet reaches a critical size beyond which further break-up ceases. The critical size to stop stripping is governed by the ratio of inertial forces to the surface tension of the liquid. The stripping mode has been verified and discussed in detail by Unal (1989). When the relative velocity between the gas and droplet becomes critical, the droplet may inflate like a parachute and burst into showers of fine droplets. In both cases, a bimodal size distribution of droplets in the spray is expected (figure 4).

In contrast, the ultrasonic gas atomization appears to have a single step liquid disintegration process. It is generally argued that the high-velocity pulsed gas travels

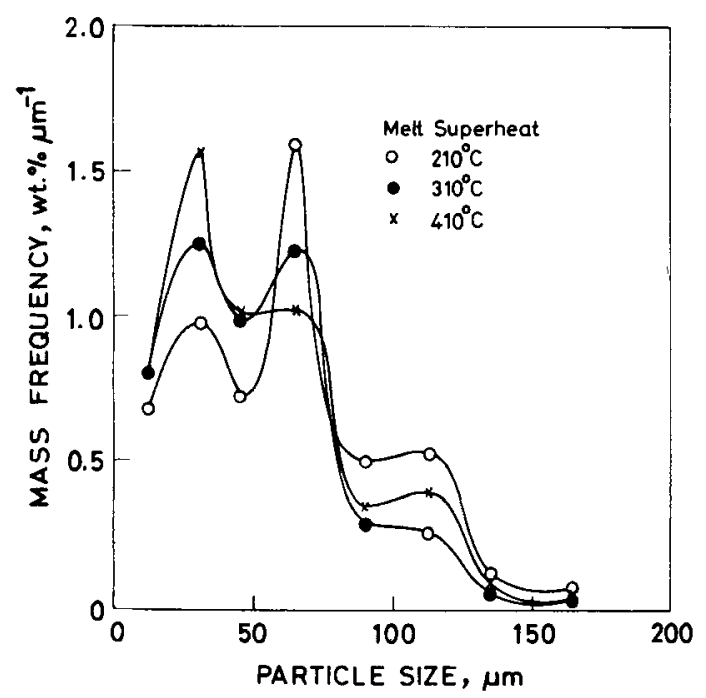

Figure 4. Mass frequency plot showing bimodal size distribution of droplets in $\mathrm{Sn}-20 \% \mathrm{~Pb}$ alloy. 
as discrete particles. The liquid stream responds on impact as a solid with low shear resistance. This hypothesis is believed to be reasonable for small powder size and a narrow size distribution of droplets in this process (Grant 1978; Ricks et al 1986).

The above discussion clearly indicates that the size distribution of droplets in the spray is primarily governed by the configuration of the gas-metal stream and the design of the atomization nozzle. In major instances the size distribution of droplets is represented by a log-normal distribution which is based on the early correlation of Lubanska (1970) between the median particle diameters and gas-metal flow rate for a variety of liquids. However, our recent investigation (Singh and Ojha 1991) suggests a bimodal size distribution of droplets at least in the confined gas atomization process.

\subsection{Droplets consolidation}

Subsequent to the formation of spray, the kinetic energy of the gas propels droplets towards the deposition surface. As mentioned earlier, the size and size distribution of droplets in the spray vary depending on the process variables and atomization process employed. The cooling rate of a small sized droplet is more than that of a large droplet. Consequently during impact the spray comprises a mixture of solid particles, semi-liquid/semi-solid particle as well as large fully liquid droplets. The phenomenon of coalescence of these heterogeneous nature of the spray into a fully dense preform is complex and probably less clearly understood (Lavernia 1989). Large number of droplets overspray, some deflect from the deposition surface and remaining droplets stick to the surface and contribute to the growth of the deposit. In a recent study by Ojha et al (1992), it has been shown that a significant amount of the oversprayed $\mathrm{Al}-\mathrm{Pb}$ powders contained specific features as they bounced off the surface.

Mathur et al (1989) analysed the consolidation behaviour of droplets on a substrate. The thermal state of droplets as well as the surface of the preform during deposition were shown to influence the growth of the preform. For example, if a solid particle impacts on a solid surface, the probability of its deflection is high compared to the impact of a semi-solid particle on a semi-liquid surface of the preform. Similarly liquid droplet in the spray can adhere to the deposition surface in any physical state. Although the yield of the preform is high under relatively hot spray conditions the volume fraction of liquid pool on the deposition surface increases. The resulting solidification structure resembles that of a conventional casting. Further, high-velocity gas jets may cause splashing of the liquid from the deposition surface. On the other hand, if the volume fraction of solid particles is high in the spray, it may lead to considerable porosity in the preform. These effects require an optimum control of the process variables in the spray forming process to produce a high density preform with the maximum yield of deposition.

\section{Model of heat flow in spray forming}

The gas serves two basic purposes in the spray forming process. Initially it transfers part of its kinetic energy to disintegrate the melt into droplets and accelerate them towards the deposition surface. Finally it extracts heat from droplets during flight and also from the top surface of preform during deposition. In the past various models have been developed to account for this effect (Guitierrez et al 1989; Bewley 
and Cantor 1990; Duszczyk and Estrada 1990; Mathur et al 1991). Although, several assumptions have been made in formulating these models, they provide valuable insights into process control in spray forming. A knowledge of heat transfer is also essential to understand the microstructure evolution of the preform (Bewlay and Cantor 1991; Singh et al 1992). The ultimate objective of any such model is to predict the thermal history of droplets during flight and preform during deposition.

\subsection{Thermal history of droplets}

The forced convective cooling at the droplet gas interface depends on the size of the droplet and its velocity relative to the gas stream. The velocity of a droplet can be calculated from the momentum equation (Szekely 1979) which relates to the acceleration of a particle moving in the gas field as

$$
\mathrm{d} v_{d} / \mathrm{d} t=\left(3 C_{D} \rho_{g} / 4 \mathrm{~d} \rho_{d}\right)\left(v_{g}-v_{d}\right)\left|v_{g}-v_{d}\right|
$$

The expression for drag coefficient $C_{D}$ is obtained from Kurten (1978) which is applicable for a wide range of Reynolds number. In our model, the value of $C_{D}$ is taken as 0.4. Wolf and Anderson (1965) have shown that this value of drag coefficient is reasonable for different velocities of droplets observed in gas atomization.

Figure 5 shows the calculated velocities of droplets of a hypoeutectic cast iron. It is worthwhile to notice that a $25 \mu \mathrm{m}$ size droplet attains maximum velocity of $215 \mathrm{~ms}^{-1}$ compared to that of $70 \mathrm{~ms}^{-1}$ for a large size droplet of $140 \mu \mathrm{m}$.

The temperature and cooling rate of a droplet in flight trajectory is determined by heat balance. For Newtonian cooling condition (Clyne et al 1984), the thermal history of a droplet is obtained as

$$
\rho_{d} C_{p}^{\text {eff }}(\mathrm{d} T / \mathrm{d} t)=6 h\left(T-T_{0}\right) / \mathrm{d}
$$

$C_{p}^{\text {eff }}$, being the specific heat of a droplet for its appropriate physical state and $h$, the convective heat transfer coefficient at the droplet-gas interface. The velocity dependent

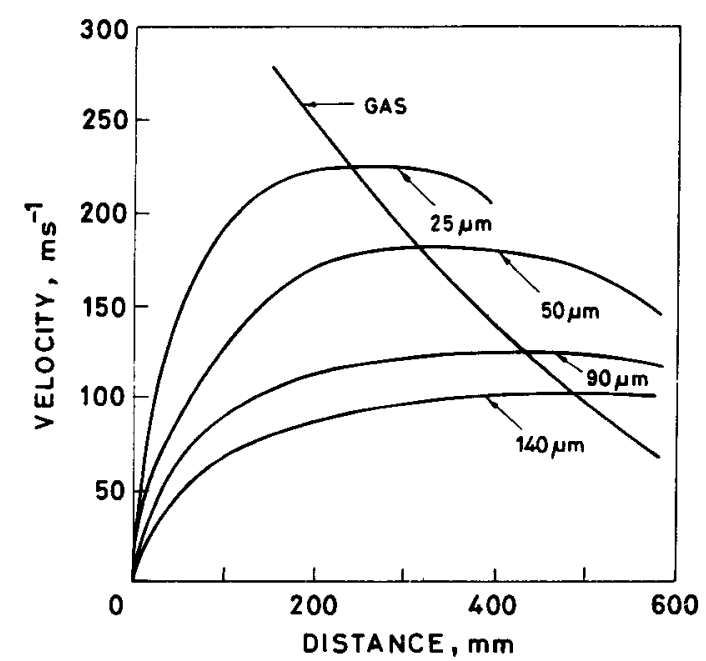

Figure 5. Variation in velocity profile of droplets during flight in the gas stream. 


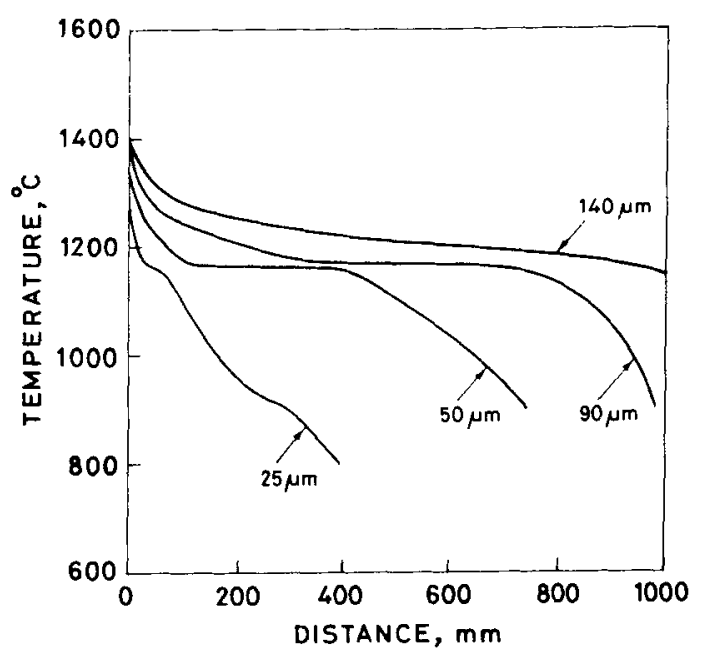

Figure 6. Temperature profile of droplets as a function of flight distance.

value of $h$ is calculated by the expression of Ranz and Marshall (1952).

$$
h=2 k_{g}\left[1+0.3 \operatorname{Re}^{0.5} \operatorname{Pr}^{0.33}\right] / \mathrm{d}
$$

The temperature profile of the droplets according to their locations in the flight trajectory is presented in figure 6. The plot indicates that droplets less than $25 \mu \mathrm{m}$ in size completely solidify during impact onto the substrate whereas droplets greater than $100 \mu \mathrm{m}$ size remain in fully liquid state. Furthermore, droplets of intermediate sizes could be perceived to be in the mushy state.

\subsection{Heat transfer during deposition}

It is obvious from the above discussion that upon arrival at the deposition surface, the spray comprises of a mixture of solid, mushy and liquid droplets. This situation is shown schematically in figure 7 . Droplets of the spray consolidate into a thick deposit subsequent to their impingement on the substrate. The net heat flux arriving at the substrate depends on thermal state of droplets. This can be expressed as

$$
\mathrm{d} H_{\mathrm{sp}} / \mathrm{d} t=0 \cdot 7 Q_{m} \Sigma\left[f_{d i}\left\{C_{p i} T_{i}+\left(1-f_{d i}\right)\right\} L\right]
$$

where subscript $i$ stands for the $i$ th size of droplet in the spray, $Q_{m}$, the melt flow rate and $L$, the heat of fusion of metal. The size distribution of droplets in our study is determined experimentally by atomization of the melt and collecting and sizing the particles. The average temperature of the spray can then be obtained as

$$
T_{\mathrm{sp}}=\left[H_{\mathrm{sp}}-\left(1-f_{s}\right) L Q_{m}\right] / Q_{m} \cdot C_{p}^{\mathrm{eff}}
$$

where $f_{s}$ is the fraction of solid in the agglomerate at the point of impingement. Thus, $T_{\mathrm{sp}}$ can be determined if $f_{s}$ is known. As a first step to determine $f_{s}$ the effective enthalpy of the spray is first computed.

$$
H_{\mathrm{sp}}=f_{s} H_{s}+\left(1-f_{s}\right) H_{l}
$$




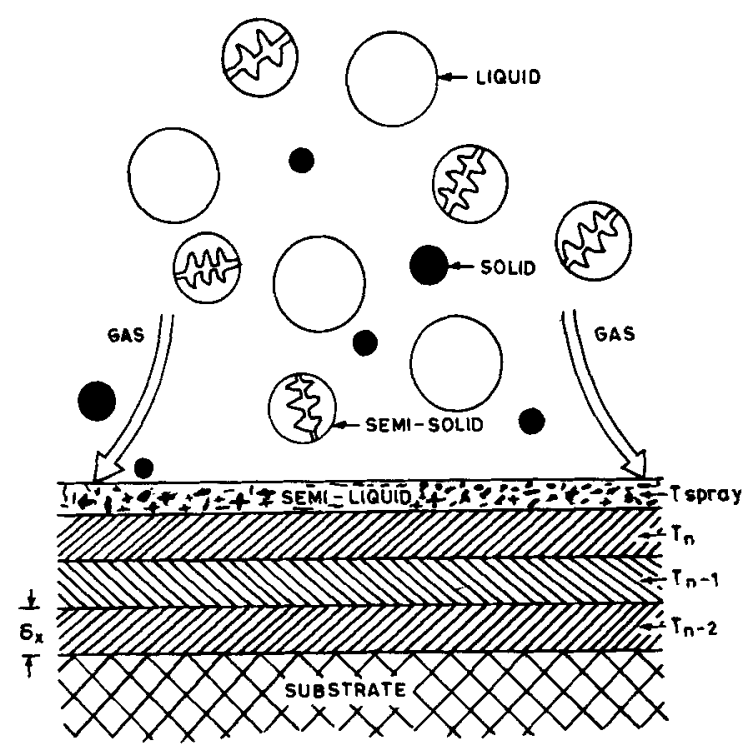

Figure 7. Schematic illustration of thermal state of droplets during deposition.

where $H_{s}$ and $H_{l}$ are the enthalpies of solid and liquid respectively. Next, if $H_{\mathrm{sp}} \leqslant H_{s}$ then $T_{\mathrm{sp}} \leqslant T_{s}$. Further if $H_{s}<H_{\mathrm{sp}}<H_{l}$ then the aggregate exists in mushy-state. This can determine $f_{s}$ conclusively.

Once the arrival of heat flux on the substrate is determined, the next step is to obtain the dissipation of heat from the deposition surface by convection $\left(H_{g}\right)$ and conduction $\left(H_{c}\right)$ as

$$
\begin{aligned}
& H_{g}=A_{s} h_{g}\left(T_{\mathrm{sp}}-T_{0}\right) \\
& H_{c}=A_{s} K_{s}\left(T_{n}-T_{n-1}\right)
\end{aligned}
$$

where $A_{s}$, the deposition area, $h_{g}$, the forced convective heat transfer coefficient at the substrate gas interface and $K_{s}$, the thermal conductivity of the preform material. The value of $h_{g}$ is obtained for impingement of the gas normal to a flat plate in lamellar flow condition (Szekely 1979).

Subsequently a heat balance between the heat flux and heat dissipation rate is established to compute the temperature and cooling rate of the top surface of the preform at node points by numerical technique (Singh 1991).

Figure 8 shows the cooling rate of the spray-deposit of a cast iron. It indicates that the cooling rate of preform during initial stages of deposition is $5 \times 10^{4} \mathrm{Ks}^{-1}$ which slows down to $3 \times 10^{3} \mathrm{Ks}^{-1}$ at a distance of $1.5 \mathrm{~cm}$ from the substrate. An understanding of heat transfer is often useful to achieve a steady-state deposition condition in spray forming.

\section{Microstructural characteristics}

A variety of microstructures is observed in the spray deposit depending on the alloy composition, the nature of the spray and the deposition condition of the droplets. 


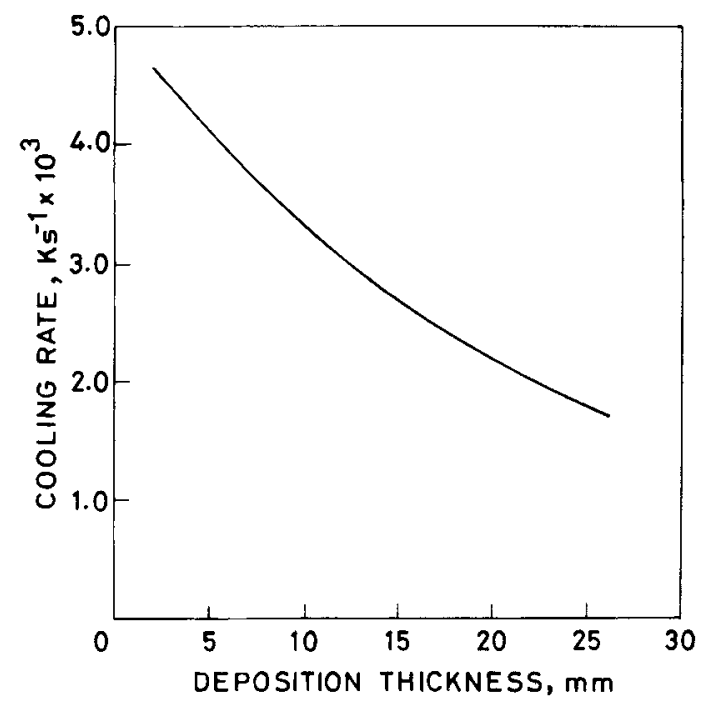

Figure 8. Cooling rate of the top surface during spray deposition of a cast iron.

Some of the microstructural observations made in the preform of steels and Al-alloys in our work are presented and discussed in this section.

\subsection{Solidification structure}

A high speed tool steel has revealed equiaxed grains with uniform distribution of carbides in the central region of the preform (figure 9a). However, towards the periphery and top surface of the deposit even prior particle splat boundaries are discernible (figure 9b). An analysis of heat flow indicated that droplets $<30 \mu \mathrm{m}$ size completely solidified prior to impact on the deposition surface whereas droplets up to $100 \mu \mathrm{m}$ size arrived in the mushy-state. Further, the confined gas atomization process employed to generate the spray provides small size droplets in the periphery of the spray cone whereas the core of the spray contains relatively large size droplets (Ojha and Singh 1991). As a result, relatively high heat exchange rate between small size droplets and gas generates large fraction of solid particles in the periphery of the deposit. In contrast a coalescence of the spray, with relatively large fraction of droplets in mushy-state, occurs in the centre of the deposit.

Spray casting of $\mathrm{Al}-4 \mathrm{Cu}-20 \mathrm{~Pb}$ alloy (Ojha et al 1992) has invariably indicated equiaxed grains throughout the deposit with variation in grain size from $20-25 \mu \mathrm{m}$ (figure 10a). The $\mathrm{Pb}$ particles uniformly distributed in Al-matrix are observed (figure 10b). Since the melt was atomized and spray deposited from a relatively high superheat to avoid liquid immiscibility in this system, most droplets arrived on the deposition surface in the liquid state. Impingement of the gas stream on the deposition surface provides rapid solidification of the liquid on the deposition surface. Interestingly, the preform of Al-Si eutectic alloy (Ojha et al 1991) has revealed a large volume fraction of primary phase with spherical morphology (figure 11a) in contrast to a complete equiaxed morphology (Ojha and Satyanarayana 1992) in Al-6.5 $\mathrm{Si}-0 \cdot 3 \mathrm{Mg}$ alloy (figure $11 \mathrm{~b}$ ). The large volume fraction of the primary phase in a 

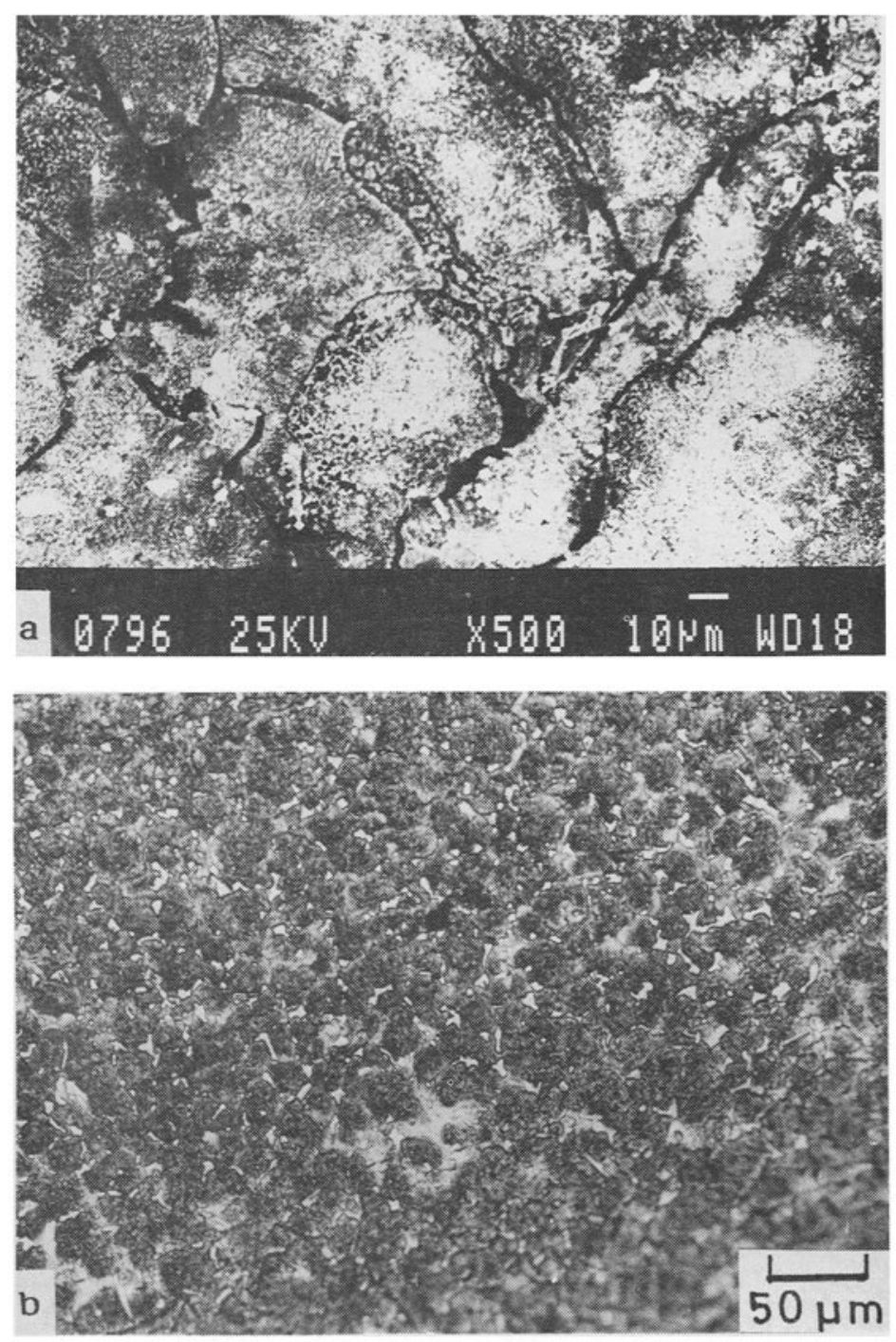

Figure 9. Microstructure of a spray-deposited high speed steel showing (a) prior particle/ splat boundaries and (b) equiaxed morphology in the centre of the deposit.

eutectic alloy led us to indirectly estimate $35 \mathrm{~K}$ undercooling of the melt prior to solidification of the liquid on the deposition surface.

\subsection{Origin of microstructures}

The microstructural features generated in the preform is a combined consequence of the phenomenon which occurs in droplets during flight and their coalescence on the deposition surface. As mentioned earlier, the spray contains droplets with different sizes and size distribution, velocities and thermal states on the point of impingement (figure 7). If the rate of arrival of droplets is such that the heat flux accompanying 

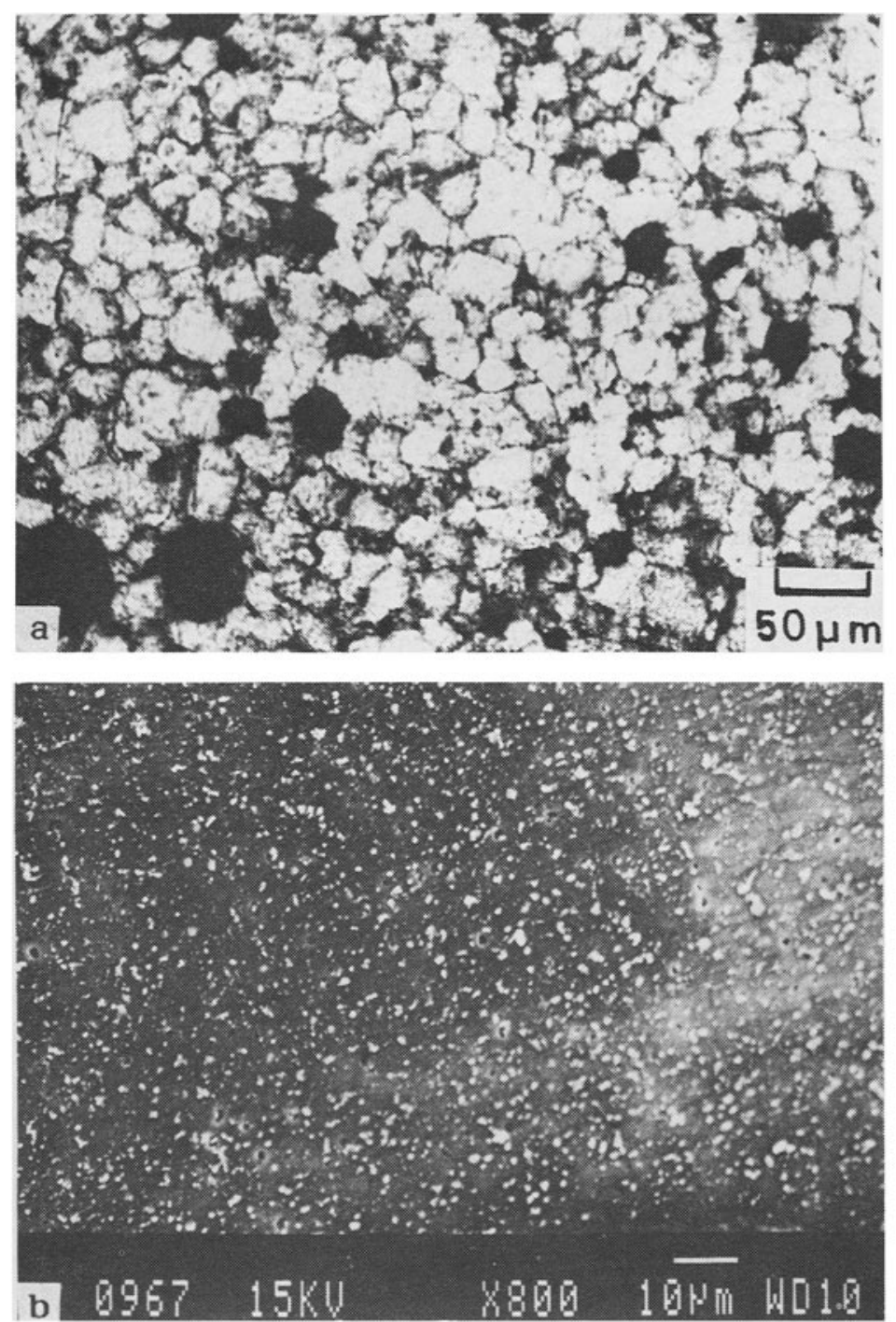

Figure 10. Microstructure of an $\mathrm{Al}-4 \mathrm{Cu}-20 \mathrm{~Pb}$ alloy showing (a) equiaxed morphology and (b) fine dispersion of $\mathrm{Pb}$ particles in Al-matrix.

them is less than the rate at which heat is extracted, then prior particle boundaries or discrete layer of splat boundaries are generated in the preform (Brooks et al 1977a). Since the individual droplet spreads upon impact to form a splat and because the heat is extracted rapidly each splat solidifies before the arrival of the next droplet. Ultimately this condition of spray-deposition gives rise to a deposit which consists of an agglomerate of splats (figure 9b). Such microstructures have also been observed in Al-transition metal alloys by Kim and Jones (1981). In this case the preform may have large amounts of porosity. Consequently such preforms require further processing to remove porosities and prior particle boundaries.

In another situation, when the rate of arrival of droplets in liquid or mushy-state 

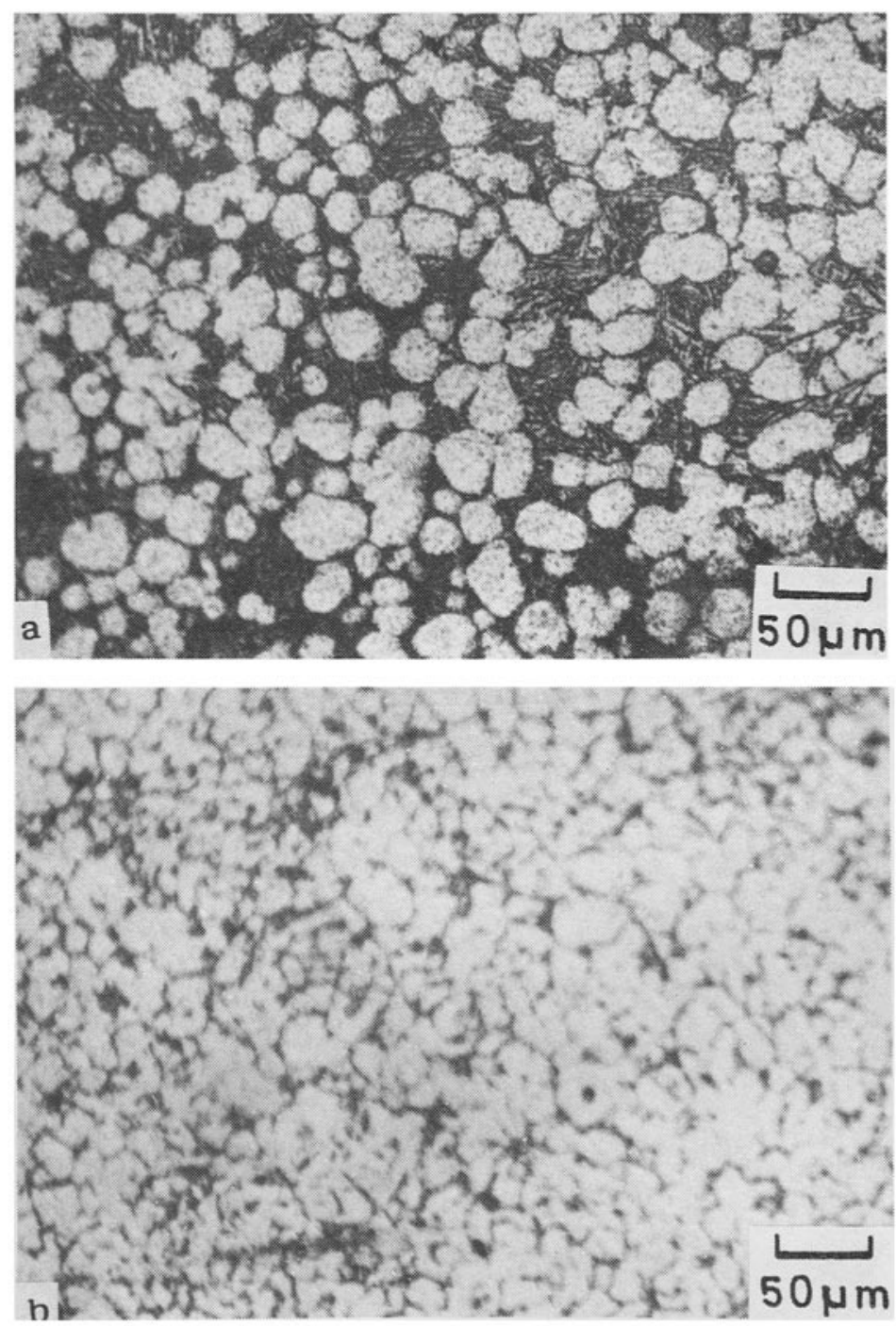

Figure 11. Microstructure showing (a) spherical morphology of the primary phase in $\mathrm{Al}-\mathrm{Si}$ eutectic and (b) equiaxed grains in $\mathrm{Al}-6.5 \mathrm{Si}-0.3 \mathrm{Mg}$ alloy.

is such that the heat flux is balanced by the heat extraction rate, the individual droplets do not solidify before the arrival of subsequent droplets. As a result, the spray deposition condition gives rise to a liquid pool on the deposition surface. In this case, the porosity of the deposit is greatly reduced and an equiaxed morphology is developed in the preform. Singer and Evans (1983) suggested that equiaxed morphology is the consequence of large nucleation sites in the liquid arising from fine dendritic debris. The mechanical momentum transferred by high velocity droplets on deposition surface creates considerable fluid flow and results in shearing of dendrites of the semi-liquid or semi-solid phase. The undercooling of the liquid phase on the deposition surface has also been suggested by Ojha et al (1991) to enhance the nucleation frequency of crystals. In yet another investigation by Lavernia (1989), 
the origin of fine equiaxed grain morphology in aluminium $\times 2020$ alloy has been proposed to be a result of recrystallization in the preform during or after deposition.

Often both the situations arise during spray-deposition. Initially, when droplets make an impact on a conductive substrate, the heat extraction rate is more than the heat flux arriving on the substrate. As the preform grows, the heat extraction rate slows down by the heat resistance offered by the preform material. Subsequently a steady-state heat transfer condition is maintained during further growth of the preform. However, towards the end of deposition, the melt flow rate is reduced due to decrease in the liquid level and metallostatic pressure in the crucible. When the same gas pressure is still maintained the fraction of small size droplets increases in the spray. This results in further microstructural transition in the preform arising from lower enthalpy of the spray. Recently the effect of spray enthalpy on such microstructural transition during spray deposition of $\mathrm{Sn}-\mathrm{Pb}$ alloys has been analysed by Bewley and Cantor (1991). The ability of the spray forming process to generate refined equiaxed microstructure with low segregation is a major benefit in alloy development.

\section{Conclusion}

An exciting new era in near-net shape manufacturing has been ushered in by spray forming. Considering that it is only two decades since the idea of spray forming was pioneered in University College of Swansea, it is amazing how commercialization of this process has already taken place for quite a few products of both ferrous and non-ferrous alloys. Numerous universities and $R \& D$ organisations the world over are presently active in research and development work to understand and exploit the benefits of spray forming technology to meet some of the increasing demands of materials and products in the next generation.

With the growing importance of more flexible manufacturing processes and high-quality products in so many high-tech sectors, spray forming has indeed emerged as a great blessing to manufacturers as well as users of such products. The Indian industry will do well to understand and appreciate the considerable potential of spray forming to embark on indigeneous R \& D in a big way to ensure self-reliance in this strategically important and potentiaily powerful technology.

\section{Acknowledgements}

The author is thankful to Professors T R Anantharaman, P Ramachandra Rao and $S$ Lele for consistent encouragement and useful suggestions. Dr S N Singh and Shri O P Pandey have helped, in no small measure, in process design and experimentation and Dr N S Mishra of R \& D, SAIL in the mathematical modelling of the process. The valuable discussion with Dr K G Satyanarayana, Scientist, RRL, Trivandrum and currently Jubilee Fellow at Banaras Hindu University is acknowledged.

\section{References}

Anantharaman T R and Suryanarayana C $1971 \mathrm{~J}$. Mater. Sci. 61111

Ando T, Lavernia E J and Grant N J 1986 Mater. Letts. 517 
Beddow J K 1978 in The production of metal powders, (London: Hyden \& Sons)

Bewley B P and Cantor B 1990 Met. Trans. B21 899

Bewley B P and Cantor B 1991 J. Mater. Res. 61433

Bricknell R H 1986 Met. Trans. A17 583

Brooks R G, Leatham A G, Coombs J S and Moore C 1977a Metall. Met. Form. 91

Brooks R G, Moore C, Leatham A G and Coombs J S 1977b Powder Met. 2100

Chen H S and Miller C E 1970 Rev. Sci. Instrum. 411237

Clyne T W, Ricks R A and Goodthew P J 1984 Int. J. Rapid Solidification 159

Duszczyk J and Estrada J L 1990 J. Mater. Sci. 251381

Gordon G D 1959 J. Appl. Phys. 301759

Grant N J 1978 in Rapid solidification processing: principle and technology, (eds) R Mehrabian, B H Kear and M Cohen (Baton Kouge: Claitor's Pub. Div. ) p. 230

Guitierrez E, Lavernia E J, Trapaga G, Izekely J and Grant N J 1989 Met. Trans. 2071

Ikawa Y 1990 iSIJ Int. 30756

Jones H 1973 Rep. Progr. Phys. 361425

Jones H 1986 Proc. Structural metals by rapid solidification, (eds) F H Froes and S J Savage (Orlando: ASM International) p. 77

Kim M H and Jones H 1981 Rapidly quenched metals IV,(eds) T Masumoto and K Suzuki (Sendai:The Japan Institute of Metals) p. 85

Klar E and Fesko J W 1984 Metals Handbook, (Metals Park, OH: ASM) Vol. 7, p. 25

Kurten $J 1978$ in Bubbles, drops and particles, (New York: Academic Press)

Lane W R 1951 Indian Engg. Chem. 431312

Lavernia E J 1989 Int. J. Rapid Solidification 547

Lavernia E J and Grant N J 1986 Mat. Powder Rep. 4255

Lavernia E J and Grant N J 1988 Mat. Sci. Engg. 98381

Lawley A 1986 J. Metals 3815

Lawley A, Mathur P, Apelian D and Meystel A 1990 Powder Met. 33109

Leatham A F, Elias L, and Ogilvy A 1991 Met. Powder Rep. 4638

Lubanska H $1970 \mathrm{~J}$. Metals 2245

Magusar J, Lavernia E J, Domalavage P, Harling O K and Grant N J 1984 J. Nucl. Mater. 122-123 789

Mathur P, Annavarapu S, Apelian D and Lawley A 1991 Mater. Sci. Engg. A142 261

Mathur P. Apelian D and Lawley A 1989 Acta Met. 37429

Ojha S N, Jha J N and Singh S N 1991 Scr. Met. Mater. 25443

Ojha S N, Pandey O P, Tripathi B, Kumar M and Ramachandra C 1992 Mater. Trans. JIM (in press)

Ojha S N and Satyanarayana K G 1992 (unpublished work)

Ojha S N and Singh S N 1991 J. Mater. Sci. Letts. 10893

Pandey O P and Ojha S N 1991 Powder Met. Int. 23291

Ranz W E and Marshall W R 1952 Chem. Engg. Prog. 48173

Rickinson B A, Kirk F A and Davies D R G 1981 Powder Met. 11

Ricks R A, Adkins N J E and Cyne T W 1986 Powder Met. 2927

Savage $S \mathrm{~J}$ and Froes F H $1984 J$. Metals 3620

See J B and Johnston G H 1978 Powder Tech. 21118

Singer A R E 1970 Met. Mater. 4246

Singer A R E 1972 J. Inst. Met. 100185

Singer A R E and Evans R W 1983 Met. Technol. 1051

Singh S N 1991 Development and analysis of an atomization process for spray deposition, $\mathrm{Ph} . \mathrm{D}$. thesis, Banaras Hindu University, Varanasi

Singh S N and Ojha S N 1991 Metals, Materials \& Processes 353

Singh S N, Mishra N S and Ojha S N 1992 Steel Res. 6312

Szekely J 1979 Fluid flow in metals processing, (New York: Academic Press) p. 261

Taylor G I 1950 Proc. R. Soc. A201 192

Unal A 1987 Mater. Sci. Technol. 31029

Unal A 1989 Met. Trans. B20 61

Williams B 1980 Met. Powder Rep. 10464

Wolf H E and Anderson W H 1965 Proc. 5th Int. Shock tube symposium, p. 1153 